\title{
Approach to hypertension in the elderly
}

\author{
Çağlar ALP' ${ }^{1}$, Taner SARAK², Aydın ÇiFÇỉ ${ }^{3}$, Mehmet KABALCI ${ }^{4}$ \\ ${ }^{1}$ Osmancık Devlet Hastanesi Kardiyoloji Bölümü, Çorum/Türkiye \\ ${ }^{2}$ Kırıkkale Üniversitesi Tıp Fakültesi Kardiyoloji Anabilim Dalı, Kırıkkale/Türkiye \\ ${ }^{3}$ Kırıkkale Üniversitesi Tıp Fakültesi İç Hastalıkları Anabilim Dalı, Kırıkkale/Türkiye \\ ${ }^{4}$ Kırıkkale Üniversitesi Tıp Fakültesi Kalp Damar Cerrahi Anabilim Dalı, Kırıkkale/Türkiye
}

\section{öz}

Hipertansiyon çağımızın en önemli hastalıklarından biri ve önemli bir kardiyovasküler risk faktörüdür. Tüm dünyada ortalama yaşam süresi uzamakta ve bunun sonucu olarak yaşlı nüfus artmaktadır. İleri yaş artmış hipertansiyon prevelansı ile birliktedir. Türkiye'de hipertansiyon prevelansı 65 yaş üstünde \%75'e ulaşmaktadır. Yaşlılardaki hipertansiyon; hem etiyopatogenez hem de tanı ve tedavi açısından diğer yaş gruplarından birtakım farklılıklar gösterir.

Anahtar kelimeler: Hipertansiyon, yaşlılar, etiyopatogenez, tedavi

\section{ABSTRACT}

Hypertension is one of the most important diseases of our age and an important cardiovascular risk factor. The average life span in the whole world is prolonged, and as a result, the elderly population is increasing. Advanced age is associated with increased hypertension prevalence. The prevalence of hypertension in Turkey is reaching $75 \%$ over 65 years old. There are some differences hypertension in the elderly from other age groups in terms of etiopathogenesis, diagnosis and treatment.

Keywords: Hypertension, elderly, etiopathogenesis, treatment 


\section{Giriş}

Kan basıncını oluşturan parametreler kalp debisi ve periferik vasküler dirençtir. Hipertansiyon bu parametrelerdeki değişikliklere bağlı gelişmektedir. Hipertansiyon dünyada morbidite ve mortalitenin en önde gelen nedenlerindendir ve giderek artan bir halk sağlığı problemi haline gelmiştir. Hipertansiyon prevelansı genel popülasyonda \%3045 civarında tespit edilmiştir; bu oran yaşla birlikte artış göstermektedir (grafik 1) ve ülkeden ülkeye değişiklikler vardır [1-4]. Türkiyede bu oran PatenT2 çalışmasında tüm populasyonda \%31,8 olarak tespit edilmiştir [2]. 65 yaş üstünde bu oran \%75'e ulaşmaktadır. Kan basıncı sirkadiyen ritm göstermekte olup genellikle sabahları en yüksek değerlerde iken geceleri en düşük seviyelerdedir.

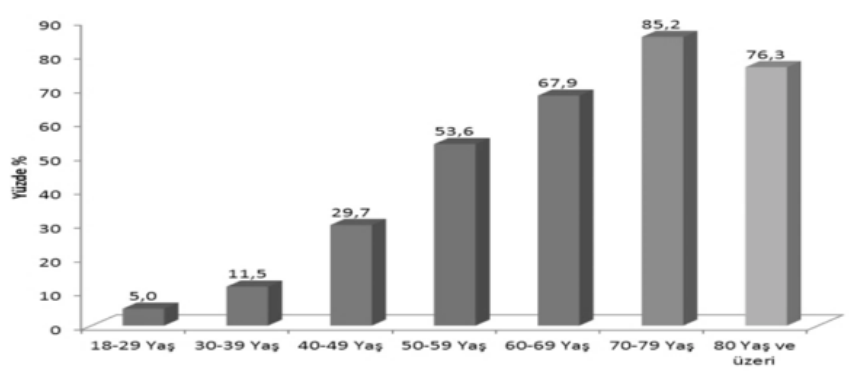

Grafik 1: Türkiye'de yaşa göre hipertansiyon prevalansı PatenT2 çalışması

\begin{tabular}{lcc}
\hline Tablo 1: JNC 7 raporuna göre HT & sınıflaması & \\
\hline KATEGORi & SisTOLIK & DIASTOLIK \\
\hline NORMAL & $<120$ & $<80$ \\
\hline PREHIPERTANSIYON & $120-139$ & $80-89$ \\
\hline EVRE 1 HIPERTANSIYON & $140-159$ & $90-99$ \\
\hline EVRE 2 HIPERTANSIYON & $\geq 160$ & $\geq 100$
\end{tabular}

Pratik uygulamada bu kan basıncı değerleri güncel kılavuzlara göre değerlendirmekte olup sürekli güncellenmektedir. En son Amerika Birleşik Devletleri Birleşik Ulusal Kurul 7 (JNC VII) ve Avrupa kardiyoloji derneği (ESH/ESC) 2013 kılavuzuna göre bu sınıflama Tablo 1 ve 2'de olduğu gibidir. JNC VIII kılavuzunda sınıflamada değişiklik yoktur. NICE 2011 ve CHEP Kanada 2012 kılavuzlarında ambulatuvar kan basıncı takibi (AKBM) veya evde kan basıncı ölçümleri yapılmasını özellikle vurgulamıştır. Bu kılavuzlardan anlaşılacağı üzere genel olarak sistolik kan basıncının 140mmHg, diyastolik kan basıncının da 90 mmHg veya üzerinde olması ya da kişinin antihipertansif ilaç kullanıyor olması hipertansiyon olarak tanımlanmaktadır [6].

\begin{tabular}{l|c|c|}
\hline \multicolumn{2}{l}{$\begin{array}{l}\text { Tablo 2: ESH/ESC (2013) } \\
\text { Kılavuzuna göre HT sınıflaması }\end{array}$} \\
\hline KATEGORi & sisTOLiK & DiASTOLiK \\
\hline OPTIMAL & $<120$ & $<80$ \\
\hline NORMAL & $120-129$ & $80-84$ \\
\hline YÜKSEK NORMAL & $130-139$ & $85-89$ \\
\hline EVRE 1 HIPERTANSIYON & $140-159$ & $90-99$ \\
\hline EVRE 2 HIPERTANSIYON & $160-179$ & $100-109$ \\
\hline EVRE 3 HIPERTANSIYON & $>180$ & $>110$ \\
\hline IZOLE SISTOLIK HT & $\geq 140$ & $<90$ \\
\hline
\end{tabular}

Son olarak yayınlanan ESC/ESH 2013 ,JNC 8 ve ASH/ISH kılavuzları önceki kılavuzlardan farklı olarak yaşlılarda hipertansiyon tanısı ve tedavisi için farklı önerilerde bulundu. İlk olarak 80 yaş üzeri hastalarda hipertansiyon tedavisi için 150/90 (ESC/ESH 160/90) değeri hedef olarak gösterildi. $\mathrm{KBH}^{\prime}$ Iılarda ve diyabetiklerde hedef tansiyon değeri 130/80 yerine 140/90 (ESC/ESH için 140/85) olarak önerildi. Kılavuzlarda 60-80 yaş arasındaki hastalar için farklı yaklaşımlar mevcuttur. JNC 8 de $>60$ yaş grubu için tedavi başlama sınırı 150/90 olarak önerilirken ASH/ISH kılavuzu bu grup için tedavi başlama sınırını 140/90 olarak önerildi. ESC/ESH kılavuzunda "yaşlı" (elderly) kelimesi kullanıldı ve bunlarda tedavi sınırı 160/90 verildi. "Yaşlı” grup için net bir yaş belirtilmedi [7 ].

\section{Yaşlıda Hipertansiyon}

Arterial kan basıncı kalp debisi ve periferik arteryel direnç tarafından oluşturulur. Hipertansiyona neden olan faktörler bu ikisinden birinde veya her ikisinde artışa yol açmak suretiyle etki ederler. Özellikle genç hastalarda kalp debisinin artmış olduğu hiperkinetik bir dolaşımın varlığı saptanabilir. Bu artış 2 farklı mekanizmayla gerçekleşebilir; intravasküler hacim artışı (önyük) veya kalbin nöral uyarımının artmasına bağlı kontraktilitenin artması. Buna rağmen hipertansiyonun ilerleyen evrelerinde artmış periferik damar direnci mevcuttur Hipertansiyona neden olan pek çok etyoloji ve patofizyolojik mekanizma mevcuttur. Kan basıncının kontrolü böbrekler, santral sinir sistemi, periferik sinir sistemi, damar endoteli ve adrenal bez etkisi ile sağlanır. Ayrıca genetik faktörler, yaşam tarzı, çevresel faktörler, hastaların fenotipik özellikleri, kan basıncı regülasyonu üzerine etki etmektedir. Patofizyolojik mekanizmalar arasında, genetik faktörler, renin-anjiyotensinaldosteron sisteminin aşırı aktivasyonu, artmış sempatik sinir sistemi (SSS) aktivitesi, Na+ tutulumu ve vazokonstrüktör maddelerin aşırı üretimi, vazodilatör maddelerin yetersiz 
üretimi, hiperinsülinemi, glukoz intoleransı, obezite, insülin direnci, diyabet ve vasküler hücre büyümesinde etkili faktörlerin aşırı üretimi sayılabilir.

Yaş ilerledikçe sistolik kan basıncı artar. Bu artış büyük damarların damar sertliği sonucu elastisitesinin azalmasına bağlı meydana gelmektedir. Büyük arterlerin media tabakasında dejeneresyon damar sertleşmesinin en büyük nedenidir [8]. Sistolik kan basıncındaki artış endotel fonksiyon bozukluğuna yol açarak, patofizyolojik sürece katkı sağlamaktadır. Yaşlı hastalarda diyastolik kan basıncı aynı kalmakta veya düşmektedir. Diyastolik kan basıncını düşmesi koroner kanlanmayı bozan bir etkendir. Diyastolik kan basıncının artmamasının nedeni olarak atım volümün yaşla birlikte azalması ön plandadır. 75 yaş üstü hastaların \% 75'inde izole sistolik hipertansiyon bulunmaktadır. Yaşlı hastalarda baroreseptör duyarlılığında azalma meydana gelir. Bunun sonucu kan basıncındaki düşüşe yanıt olarak kalp hızında ve toplam periferik damar direncinde olması gereken artış izlenemez. Barareseptör duyarlılığındaki azalmaya bağlı yaşlı hastalarda antihipertansif tedaviye bağlı ortostatik hipotansiyon görülme sıklığı artar. Ayrıca yaşlanma ile böbrek işlevlerinde bozulma, sodyum retansiyonu, çoklu ilaç kullanımı ve ek hastalıklar gibi faktörler bu yaş gurubunda antihipertansif tedaviyi güçleştirir. Yaşlı hastalarda renal arter stenezu akılda tutulması gereken diğer önemli bir nedendir [9].

Yaşlılarda antihipertansif tedavi ile ilgili çok sayıdaki randomize kontrollü çalışmarın (80 yaş ve üstü hipertansif hastaların alındığı bir çalışma dahil) hepsi kan basıncı düşüşü ile KV olaylarda azalma olduğunu göstermiştir ve ulaşılan ortalama SKB hiçbir zaman <140 mmHg olmamıştır [10]. Bunun aksine, Japonya'da yapılan iki güncel çalışmada düşük yoğunlukta KB düşürme ile yüksek yoğunlukta KB düşürme karşılaştırılmış, ama ortalama sistolik KB'nin 145 ve 142 mmHg yerine 138 ve 137 mmHg'ye düşürülmesinin yararları gözlenememiştir [11].

\section{Yaşılıarda antihipertansif tedavi}

Hipertansif hastalarda tedavide ilk seçenek diğer hastalarda olduğu gibi yaşam tarzı değişikliğidir. Yaşam tarzı değişikliğine örnek olarak obezitenin engellenmesi, tuzun azaltılması, haftada en az 3 gün 30 dakika egzersiz ve diyette doymuş yağ miktarının azaltılması verilebilir [6].

Sistolik kan basıncındaki düşüş kullanılan antihipertansif ajandan bağımsız olarak kardiovasküler yarar sağlamaktadır [12]. Avrupa Kardiyoloji Derneğinin " 2013 Arteriyel Hipertansiyon" kılavuzuna göre hipertansif hastalara diüretik, kalsiyum kanal blokeri, ACE inhibitörü ve anjiyotensin reseptör blokeri ilk seçenek olarak başlanabilir [13]. İzole sistolik hipertansiyonda ilk seçenek olarak kalsiyum kanal blokeri veya tiyazid diüretikleri önerilmektedir. JNC 7 kılavuzu da ilk seçenek olarak tiyazid diüretikleri önermekteydi. Eğer hastanın eşlik eden hastalıklarına bağlı olarak zorlayıcı endikasyonla bir tedavi alması gerekiyorsa, antihipertansif tedavi olarak bu ilaç grubu öncelikle düşünülmeli, kan basıncı kontrolüne göre ek ilaç verilmelidir.

Yaşlılarda hipertansiyon prevelansı artmaktadır. Hipertansiyon kardiovasküler hastalıklar için risk faktörü olduğu için yaşlılarda önemli bir sağlık sorunudur. Fakat yaşlılarda hipertansiyon tedavisi farklılık göstermektedir. Tedavi hastaya göre kişiselleştirilmedir. Yaşlı hastaların performansları ve ek hastalıkları kişiden kişiye farlılık gösterir. 2007 ESH/ESC kılavuzu ve diğer kılavuzlarda 1. derece hipertansiyonda yaştan bağımsız tedavi uygulanması önerilmekle birlikte, yaşlılarda antihipertansif tedavinin faydalarını gösteren tüm çalışmaların SKB $>160 \mathrm{mmHg}$ (2 ve 3. derece) değerleri bulunan hastalarda yapıldığı bilinmektedir yani yaşlılarda evre 1 hipertansiyonun tedavi etmenin ek faydası yoktur $[10,13]$. Hatta bu hastalarda tansiyonu düşürmek postüral hipotansiyon ve dolayısıyla düşme riskini artırarak ek komorbiditelere sebep olabilir.

\section{Sonuç}

80 yaş üstü hastalar için tedavi sınırı son kılavuzlarda sistolik kan basıncı >150 mmhg olarak belirtilmektedir, bu dikkate alınmalıdır. Yaşı hastalarda tedavi bireyselleştirilmeli, yaşın yanında hastaların performansları ve kırılganlıkları göz önünde bulundurulmalı, hastalar hipotansiyon ve renal fonksiyonlar açısından sıkı takip edilmelidir.

\section{Çıkar çatışması / finansal destek beyanı}

Bu yazıdaki hiçbir yazarın herhangi bir çıkar çatışması yoktur. Yazının herhangi bir finansal desteği yoktur

\section{Kaynaklar}

1. Danon-Hersch N, Marques-Vidal P, Bovet $P$ et al. Prevalence, awareness, treatment and control of high blood pressure in a Swiss city general population: the CoLaus study. Eur J Cardiovasc Prev Rehabil 2009; 16: 66-72.

2. Altun B, Arici G, Nergizoglu U et al. Renal, Prevalence, awareness, treatment and control of hypertension in Turkey (the PatenT study) in 2003. J Hypertens 2005; 23: 1817-23.

3. Aytekin T, Pala K, Irgil E, Akis N, Aytekin H. Distribution of blood pressures in Gemlik District, north-west Turkey. Health Soc Care Community, 2002; 10: 394-401.

4. Efstratopoulos AD, Voyaki SM, Baltas AA et al. Prevalence, awareness, treatment and control of hypertension in Hellas, Greece: the Hypertension Study in General Practice in Hellas (HYPERTENSHELL) national study. Am J Hypertens, 2006; 19: 53-60. 
5. Millar-Craig M, Bishop C, Raftery E. Circadian variation of bloodpressure. The Lancet 1978; 311: 795-97.

6. Chobanian AV, Bakris GL, Black HR et al. Treatment of High Blood Pressure. National Heart, I. Blood, and C. National High Blood Pressure Education Program Coordinating, Seventh report of the Joint National Committee on Prevention, Detection, Evaluation, and Treatment of High Blood Pressure. Hypertension 2003; 42: 1206-52.

7. Weber MA, Schirin EL, White W et al. Clinical practice guidelines for the management of hypertension in the community a statement by the american society of hypertension and the international society of hypertension. J Hypertens. 2014; 32: 3-15.

8. Lakatta EG, Wang M, Najjar SS. Arterial aging and 12. subclinical arterial disease are fundamentally intertwined at macroscopic and molecular levels. Med Clin North Am 2009; 93: 583-604.

9. Pearce JD, Craven BL, Craven TE, Piercy KT, Stafford JM, Edwards MS, Hans en KJ. Progression of atherosclerotic renovascular disease: A prospective populationbased study. J Vasc Surg 2006; 44: 955-62
10. Zanchetti A, Grassi G, Mancia G. When should antihypertensive drug treatment be initiated and to what levels should systolic blood pressure be lowered? A critical re-appraisal. J Hypertens 2009; 27: 923-34

11. JATOS Study Group. Principal results of the Japanese trial to assess optimal systolic blood pressure in elderly hypertensive patients (JATOS). Hypertens Res 2008; 31: 2115-27.

12. Wang JG, Staessen JA, Franklin SS et al. Systolic and diastolic blood pressure lowering as determinants of cardiovascular outcome. Hypertension 2005; 45: 907-13.

13. Mancia G, De Backer G, Dominiczak A et al. The 7. task force for the management of arterial hypertension of the European Society of $\mathrm{H}$, The task force for the management of arterial hypertension of the European Society of C: 2007 guidelines for the management of arterial hypertension. The task force for the management of arterial hypertension of the european society of hypertension (esh) and of the european society of cardiology (esc). Eur Heart J 2007;28:1462-536 